\title{
A Statistical Evaluation of the Radionuclide Inventory in the 222-S Laboratory and a Comparison with the Current Inventory Estimates
}

C. L. Painter

D. S. Daly

T. L. Welsh

September 1996

Prepared for Westinghouse Hanford Company under a Related Services Agreement with the U.S. Department of Energy under Contract DE-AC06-76RLO 1830

Pacific Northwest National Laboratory Operated for the U.S. Department of Energy by Battelle

\section{\% Battelle}




\section{DISCLAIMER}

This report was prepared as an account of work sponsored by an agency of the United States Government. Neither the United States Government nor any agency thereof, nor Battelle Memorial Institute, nor any of their employees, makes any warranty, express or implied, or assumes any legal liability or responsibility for the accuracy, completeness, or uśefulness of any information, apparatus; product, or ṕrocess disclosed, or represeñ that its, use would not infringe privately owned rights. Reference herein to any specific cominercial product process, or service by trade name, trademark, manufacturer, or otherwise does not necessarily constitute or imply its endorsement, recommendation, or favoring by the United States Goveriment or any agency thereof, or Battelle Memorial Institute. The views and opinions of authors expressed herein do not-necessarily state or reflèct those of the United States Governiment or any agency thereof:

\section{PACIFICNORTHWESTT NATIONAL LABORATORY operaited by: \\ BATTELLE \\ for the \\ UNITED STATES DEPARTMENT OF ENERGY under Contract DE-AC06-76RLO 1830}

Printed in the United States of Anierica

Available to DOE and DOE contractors from the

Office of Scientific and Technical Information, P.O. Box 62, Oak Ridge, TN 37831; prices available from (615) 576-8401.

Available to the public from the National Technical Information Service, U.S. Department of Conmerce, 5285 Port Royal Rd., Springfield; VA 22161 
PNNL - 11319

UC-721

\title{
A Statistical Evaluation of the Radionuclide Inventory in the 222-S Laboratory and a Comparison with the Current Inventory Estimates
}

\author{
C.L. Painter \\ D.S. Daly \\ T.L. Welsh ${ }^{3}$
}

September 1996

Prepared for Westinghouse Hanford Company under Contract \#820201000.

Pacific Northwest National Laboratory

Richland, Washington 99352

\footnotetext{
${ }^{1}$ Westinghouse Hanford Company
} 


\section{DISCLAIMER}

Portions of this document may be illegible in electronic image products. Images are produced from the best available original document. 


\section{Summary}

The Pacific Northwest National Laboratory (PNNL), in cooperation with Westinghouse Hanford Company (WHC) staff, statistically evaluated the 222-S Laboratory's inventory of radionuclides to predict the curie content retained in the numerous waste samples stored within the facility. The statistical evaluation results, when compared to the inventory based on methodology described in the 222-S Laboratory's Interim Safety Basis (ISB) document (Weaver 1996) suggests that Weaver's method is very conservative. A comparison of the 222-S Laboratory's radionuclide inventory predictions (defined as a percentage of the maximum allowed inventory) based on Weaver's method and the method presented in this report, is shown in Figure A.1. From Figure A.1 it is evident that the method described by Weaver may over estimate the actual inventory for each radionuclide by an order of magnitude when compared to the $99 \%$ upper confidence bound on the predicted inventory calculated in this report. Therefore, this report concludes that the actual inventory of radionuclides, which could significantly contribute to offsite dose, is less than currently predicted.

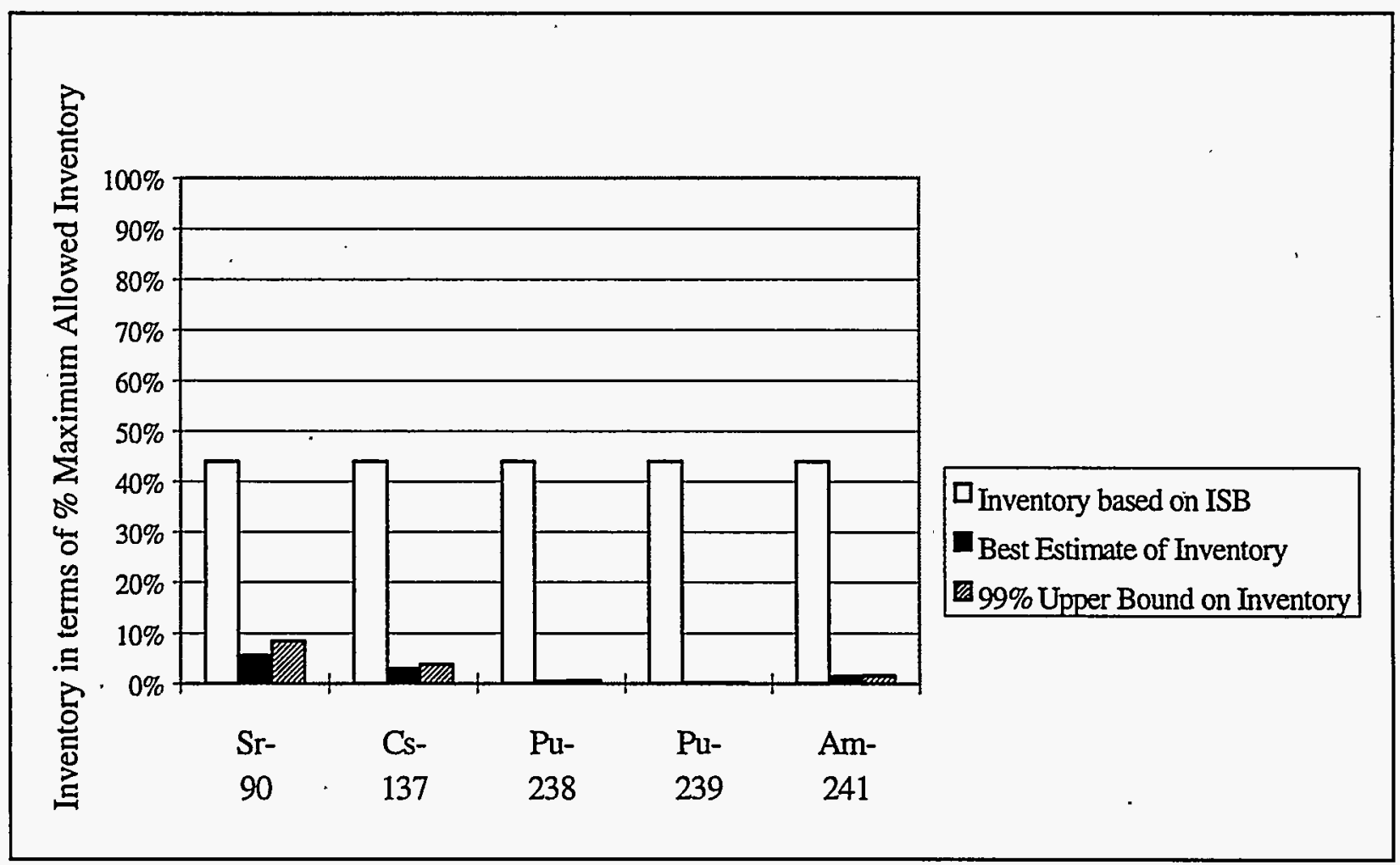

Figure S.1 A Comparison of Radionuclide Inventory Estimates Based on the ISB Accounting Method and a Statistical Bootstrapping Technique 



\section{CONTENTS}

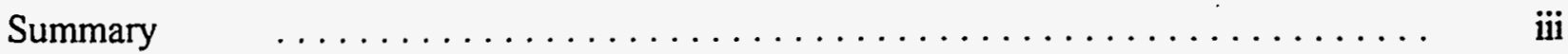

$1,0 \quad$ Introduction $\ldots \ldots \ldots \ldots \ldots \ldots \ldots \ldots \ldots \ldots \ldots \ldots \ldots \ldots \ldots \ldots \ldots \ldots$

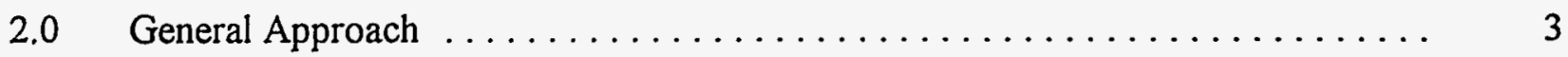

3.0 Analyses of Waste Tank Sample Data $\ldots \ldots \ldots \ldots \ldots \ldots \ldots \ldots \ldots \ldots \ldots$

3.1 Data Used in the Evaluation of 222-S Radionuclide Inventory $\ldots \ldots \ldots \quad 5$

3.2 Total Curie Estimations Based on Smoothed Bootstrapping $\ldots \ldots \ldots \quad 7$

3.3 Summary of Waste Tank Data Analysis $\ldots \ldots \ldots \ldots \ldots \ldots \ldots \ldots . \ldots \ldots$

4.0 Comparison of ISB Methodology Estimates and Bootstrapped Estimates $\ldots \ldots \quad 17$

5.0 Conclusions and Recommendations $\ldots \ldots \ldots \ldots \ldots \ldots \ldots \ldots \ldots \ldots$

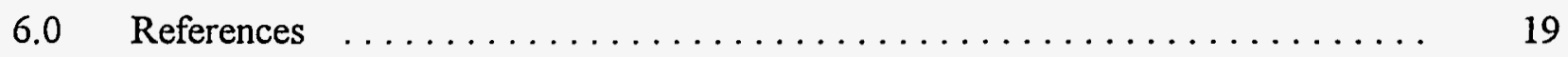

\section{FIGURES}

S.1 A Comparison of Radionuclide Inventory Estimates Based on the ISB Accounting Method and a Statistical Bootstrapping Technique $\ldots \ldots \ldots \ldots$ iii

3.1 Estimates of Sr-90 Probability Density and Distribution Function for Liquid Samples $\ldots \ldots \ldots \ldots \ldots \ldots \ldots \ldots \ldots \ldots \ldots \ldots$

3.2 Estimates of Sr-90 Probability Density and Distribution Function for Solid Samples . . . . . . . . . . . . . . . . . . . . . . 8

3.3 Estimates of Cs-137 Probability Density and Distribution Function for Liquid Samples $\ldots \ldots \ldots \ldots \ldots \ldots \ldots \ldots \ldots \ldots \ldots$

3.4 Estimates of Cs-137 Probability Density and Distribution Function for Solid Samples 
3.5 Estimates of $\mathrm{Pu}-238$ Probability Density and Distribution

Function for Liquid Samples

3.6 Estimates of Pu-238 Probability Density and Distribution

Function for Solid Samples

3.7 Estimates of Pu-239 Probability Density and Distribution

Function for Liquid Samples

3.8 Estimates of Pu-239 Probability Density and Distribution

Function for Solid Samples

3.9 Estimates of Am-241 Probability Density and Distribution

Function for Liquid Samples

3.10 Estimates of Am-241 Probability Density and Distribution

Function for Solid Samples

3.11 Total-Curie Bootstrapped-Sampling Distribution for Sr-90 $\ldots \ldots \ldots \ldots \ldots$

3.12 Total-Curie Bootstrapped-Sampling Distribution for Cs-137 ..........

3.13 Total-Curie Bootstrapped-Sampling Distribution for Pu-238 $\ldots \ldots \ldots \ldots \ldots$

3.14 Total-Curie Bootstrapped-Sampling Distribution for Pu-239 $\ldots \ldots \ldots \ldots \ldots \quad 14$

3.15 Total-Curie Bootstrapped-Sampling Distribution for Am-241 . . . . . . . .

\section{TABLES}

2.1 Radionuclide Percent Contribution to Radiological Dose

Based on 800 CESs

$3.1 \quad$ Distribution of TWINS Data $\ldots \ldots \ldots \ldots \ldots \ldots \ldots \ldots \ldots \ldots \ldots \ldots \ldots \ldots$

3.2 Summary of Best Estimate and $99 \%$ Curie Inventory Values for

Tank Samples

4.1 Current 222-S Laboratory Inventory Based on ISB Methodology $\ldots \ldots \ldots \ldots$

4.2 Estimate of Total Curies Associated with Waste Tank Samples Stored at the.222-S Laboratory as of May 30, 1996 


\subsection{Introduction}

Department of Energy contractors responsible for the safe operation of non-reactor nuclear facilities need to establish maximum inventory limits on both radioactive and hazardous materials stored, used, or processed at their facilities. These contractors need to ensure that established maximum limits are not exceeded. This necessity is derived from the requirement to demonstrate that a non-reactor nuclear facility can be safely operated during normal and abnormal conditions. The safe operation of a non-reactor nuclear facility is demonstrated, in part, by establishing operating limits based on the analyses of a well-defined set of accident scenarios and defense-in-depth practices.

Analyses of accident scenarios typically begin with a well-defined maximum quantity of radioactive or hazardous material. The maximum quantity selected ideally should bound all foreseeable operational situations. This concept is clearly stated in DOE Order 5480.23, Nuclear Safety Analysis Reports, which requires safety analysis reports (SARs) to "identify the inventory of hazardous materials (type and amount), including radioactive materials and chemical materials that could lead to a reportable event. In establishing this inventory, it should be ensured that inventories to be encountered in facility operations are adequately enveloped..."

The 222-S Laboratory has established, in Weaver (1996), that a maximum of 800 core equivalent samples (CESs) may be stored at the Laboratory. One CES is defined in Weaver (1996) to be equal to a core sample taken from a Hanford waste tank weighing 625 grams and having a specified curie content for each of several radionuclides. A 720 CES operating limit for controlling the number of samples in the Laboratory's inventory was established by subtracting $5 \%$ for a safety margin and $5 \%$ for process piping and filtration holdup.

Originally, it was thought that radiochemistry data from analyzed waste tank samples would not provide a good basis for estimating the concentration of individual isotopes in stored samples. At that time a comprehensive database of waste tank radiochemistry analyses had not been fully developed. Likewise, the analytical sampling plans were defined by the customer, and therefore, not every sample was analyzed to determine each radionuclide concentration.

It was believed that a larger and more representative set of data to determine radionuclide inventory could be obtained from a complete set of radiochemistry results taken from the analysis of 219-S liquid waste samples. The 219-S waste tank is located in the Waste Handling Facility and is the central collection point for radioactive contaminated liquid waste generated by operations in the 222-S Laboratory.

As discussed in Weaver (1996) the average concentration value for Sr-90 was obtained from 219-S waste tank samples collected over an 18-month period. By comparing this average to the maximum concentration of $\mathrm{Sr}-90$ found in samples analyzed during the same period, a dilution factor of 25,000 was determined. The dilution factor was multiplied by 2 as an added measure of conservatism and then applied to concentrations of other radionuclides detected in the 219-S waste tank samples to estimate the maximum concentration $(\mathrm{uCi} / \mathrm{gm})$ of 
each radionuclide in the defined CES. The maximum inventory permitted in the facility for a given radionuclide is therefore equal to the CES concentration multiplied by 625 grams per CES and then multiplied by 800 CES units.

A separate consideration was the maximum value of Pu-239 allowed in the facility. Instead of determining its maximum value in the same manner as the other radionuclides, the maximum limit for Pu-239 was based on maintaining the criticality designation of the 222-S Laboratory as an "isolated facility." This meant that the total allowed inventory of Pu-239 be limited to one third of its critical mass, or approximately 11 curies. Therefore, the CES concentration of $\mathrm{Pu}-239$ was defined by dividing 11 curies by $800 \mathrm{CES}$ units.

During the Interim Safety Basis (ISB) document's final approval process it was recommended that an independent method should be developed to determine that the Laboratory is indeed maintaining its inventory below the maximum inventory limits defined in Weaver (1996). In addition, as the Laboratory's predicted CES inventory approaches its maximum limit, it will become necessary to either reduce the inventory in the Laboratory by identifying a separate storage facility and physically removing the samples from the 222-S Laboratory, or by developing a more accurate method to predict the Laboratory's inventory of radionuclides. It is believed that the method developed in this report will provide an acceptable, efficient, and reasonably conservative approach for predicting curie inventory at the 222-S Laboratory without unnecessarily restricting facility operations. 


\subsection{General Approach}

The 222-S Laboratory established in Weaver (1996), through documented safety analyses, that its maximum allowed inventory is $800 \mathrm{CES}$ units. By using the CES definition presented in Weaver (1996) one can easily determine the maximum allowed curies per radionuclide permitted in the Laboratory. Combining the maximum allowed curies per radionuclide with their corresponding dose conversion factors (DCF) (Eckerman et al. 1988) and assuming that the respirable release fraction (RRF), leakpath factor (LF), atmospheric dispersion coefficient $(\mathrm{X} / \mathrm{Q})$, and breathing rate (BR) values are constant for each isotope, it is possible to estimate each radionuclides contribution to offsite dose and establish which radionuclides are the major contributors. The contribution of each radionuclide to offsite dose is shown in Table 2.1 in terms of a percent contribution.

Results shown in Table 2.1 indicate that the radionuclides Pu-238, Pu-239, and Am-241 contribute approximately $96 \%$ of the total predicted dose. If the radionuclides $\mathrm{Sr}-90$ and Cs- 137 are also included one can account for $99.7 \%$ of the total predicted dose. Therefore, for the purposes of this study, it has been assumed that only those "radionuclides of concern" (defined as Sr-90, Cs-137, Pu-238, Pu-239, and Am-241) must be accounted for in the 222-S Laboratory's inventory of radioactive material.

The Laboratory's current inventory consists primarily of samples taken from various Hanford waste tanks containing radioactive waste generated from the production of special nuclear materials during the site's production years. Since a complete set of radiochemistry data does not exist for each waste tank sample, a statistical method was developed to provide a best estimate of the total curies for each radionuclide of concern contained in waste samples reported in the 222-S Laboratory's CES database (WHC May 30, 1996). The estimates were made using a variation on a statistical technique called "smoothed-bootstrapping."

Smoothed-bootstrapping is a statistical method analogous to Monte Carlo simulation using a smoothed empirical probability distribution. The objective of smoothed-bootstrapping is to estimate the sampling distribution of an estimator of a parameter. In this case, the parameter is the total curie content and the estimator is the sum of the products of sample concentrations and masses or volumes. In any statistical assessment, the estimated sampling distribution is the key to the best "one number" estimate of a parameter and an estimate of an interval containing the parameter.

The sampling distribution estimate is obtained by repeatedly estimating the total curie inventory and tabulating these results with each result treated like an observation. The sampling distribution is similar to a histogram and the total curies best estimate, in this case, is simply the median of the bootstrap estimate (i.e., middle of the histogram), while a conseryative estimate is the 99th percentile of the bootstrap estimate (located in the far right tail of the histogram). 
Table 2.1 Radionuclide Percent Contribution to Radiological Dose Based on 800 CESs

\begin{tabular}{|c|c|c|c|c|}
\hline Isotope $^{a}$ & $\begin{array}{l}\text { Max Inventory } \\
\quad \text { (curies) }\end{array}$ & $\begin{array}{c}\text { DCF } \\
(\mathrm{mrem} / \mathrm{uCi})\end{array}$ & $\begin{array}{l}\text { Max Inventory } \\
\text { times DCF/1E-6 }\end{array}$ & $\begin{array}{c}\% \text { Contribution } \\
\text { to Dose }\end{array}$ \\
\hline $\mathrm{H}-3(\mathrm{~V})$ & 4.069 & 0.064 & $2.60 \mathrm{E}+05$ & $0.00 \%$ \\
\hline $\mathrm{C}-14\left(\mathrm{CO}_{2}\right)$ & 0.129 & 0.0235 & $3.02 E+03$ & $0.00 \%$ \\
\hline Co-60 (Y) & 8.656 & 218.7 & $1.89 \mathrm{E}+09$ & $0.01 \%$ \\
\hline $\operatorname{Sr}-90(\mathrm{Y})$ & 491 & 1298.7 & $6.38 \mathrm{E}+11$ & $3.55 \%$ \\
\hline Tc-99 (W) & 1.067 & 8.325 & $8.88 \mathrm{E}+06$ & $0.00 \%$ \\
\hline Cs-137 (D) & 1270 & 31.93 & $4.04 \mathrm{E}+10$ & $0.23 \%$ \\
\hline $\mathrm{Pm}-147(\mathrm{Y})$ & 152 & 39.22 & $5.96 \mathrm{E}+09$ & $0.03 \%$ \\
\hline $\mathrm{U}-233(\mathrm{Y})$ & $8.86 \mathrm{E}-08$ & $1.3542 \mathrm{E}+05$ & $1.20 \mathrm{E}+04$ & $0.00 \%$ \\
\hline$U-234(Y)$ & 0.293 & $1.3246 \mathrm{E}+05$ & $3.89 \mathrm{E}+10$ & $0.22 \%$ \\
\hline $\mathrm{U}-235(\mathrm{Y})$ & . $1.72 \mathrm{E}-03$ & $1.2284 E+05$ & $2.11 E+08$ & $0.00 \%$ \\
\hline $\mathrm{U}-238(\mathrm{Y})$ & $2.84 \mathrm{E}-02$ & $1.184 \mathrm{E}+05$ & $3.36 E+09$ & $0.02 \%$ \\
\hline $\mathrm{Pu}-238(\mathrm{Y})$ & 43.4 & $2.8823 \mathrm{E}+05$ & $1.25 E+13$ & $69.74 \%$ \\
\hline $\mathrm{Pu}-239(\mathrm{Y})$ & 11 & $3.08210 \mathrm{E}+05$ & $3.39 \mathrm{E}+12$ & $18.90 \%$ \\
\hline Am-241 (W) & 2.949 & $4.44 \mathrm{E}+05$ & $1.31 \mathrm{E}+12$ & $7.30 \%$ \\
\hline
\end{tabular}

" The letters shown in parentheses identify the lung clearance class used. Lung clearance class values [D (days), W (weeks), or Y (years)] characterize the chemical form assumed in the calculations and were selected based on using the most bounding value and not necessarily the value assumed in the Laboratory's safety analyses. Lung clearance class values (D, W, or $Y$ ) were selected based on the most conservative value tabulated (i.e., the worst-case scenario).

To apply the smoothed-bootstrapping technique, a set of data representative of the 222-S Laboratory inventory had to be identified. After reviewing, with 222-S Laboratory staff, the various databases containing results of radiochemistry analyses performed on numerous waste tank samples, it was decided that the post-1989 analytical data presented in the Tank Waste Information Network System (TWINS) database (PNNL June 17, 1996) was representative of the material currently stored within the 222-S Laboratory. In the bootstrap analysis we assume that this data is a random sample from all possible analyses that could have been performed on the stored samples (i.e., the data is representative of the distribution of radionuclides in the CES samples). 


\subsection{Analyses of Waste Tank Sample Data}

This section discusses the application of the smoothed bootstrap technique to predicting the curie inventory retained in the numerous waste tank samples for the radionuclides of concern and the uncertainty associated with such a prediction.

\subsection{Data Used in the Evaluation of 222-S Radionuclide Inventory}

Much work has been done in recent years to characterize the waste stored in the Hanford double-shelled and singled-shelled tanks. Radiochemistry results of numerous samples taken from various Hanford waste tanks have recently been recorded in TWINS. Moreover, Pacific Northwest National Laboratory (PNNL) has recently developed the Hanford Tank Characterization Database (TCD) Interface to allow staff at Hanford to easily extract data . from the TWINS database.

Waste tank characterization data was extracted from the TCD to characterize the 222-S Laboratory inventory. Only samples analyzed at the 222-S Laboratory were included in the analysis. Subsets, one for each radionuclide, were identified from this master data set. The TCD result types used to evaluate the 222-S Laboratory's radionuclide inventory were those reported as "Primary Results" or "Duplicate Results." Estimated results and below minimum detection limit values were excluded.

In addition, data from the CES database (WHC May 30, 1996) were used in the analysis. The CES database is a 222-S Laboratory log of samples stored at the Laboratory. It is the most accurate and up-to-date list of samples currently stored at the facility. The CES log currently lists 1055 samples (excluding KE Basin and those listed as status "D"). Approximately 1000 samples listed in the CES database were associated with waste tank samples. The remaining samples were not well defined because the identified sites (e.g., GROUT) were not meaningful to the authors. Nonetheless, these were treated like tank samples in the inventory estimation process.

The 1055 samples were divided into solid and liquid subsets containing 785 and 270 samples, respectively. The division between solids and liquids was made using the CES database variable "Type." Type "G" samples were designated liquid samples and assigned a volume value of $125 \mathrm{ml}$ (a typical liquid grab sample volume). The remaining samples were assumed to be solid samples. Masses, in terms of grams, were determined from the value listed under the CES database variable "Mass." In those cases where no mass was listed, the mass was assigned a value based on 625 grams times the sample's assigned CES value (e.g., $0.3 \mathrm{CES}$ units times 625 grams is equivalent to 187.5 grams).

The samples were identified with 115 different sites. Two or more samples were listed for 89 sites. Three or more samples were listed for 69 sites. This distribution of samples across 115 sites is important to note because the concentration data used to predict radiochemistry in all samples was derived from as few as 13 tanks. Radiochemistry predictions for samples from the 115 sites based on samples drawn from as few as 9 tanks must be viewed cautiously. Though every effort has been made to produce conservative predictions using the best 
available data, the validity of these predictions is based on the validity of the assumption that the TCD data are representative of what is currently stored in the 222-S Laboratory.

Table 3.1 presents the distribution of TCD samples for the five selected radionuclides of concern. . The entries represent the number of records reported in the TCD database. The number of tanks associated with each number of samples in each subset is listed in parentheses for both the solid and liquid samples.

Table 3.1 Distribution of TWINS Data

\begin{tabular}{lcccc}
\hline & \multicolumn{2}{c}{ TWINS } & \multicolumn{2}{c}{ Type } \\
\hline Radionuclide & $\begin{array}{l}\text { Total \# of } \\
\text { samples listed } \\
\text { in TCD }\end{array}$ & $\begin{array}{l}\text { Total \# of } \\
\text { samples listed as } \\
\text { "passed QC" }\end{array}$ & $\begin{array}{l}\text { Total \# of solid } \\
\text { samples (tanks) }\end{array}$ & $\begin{array}{l}\text { Total \# of liquid } \\
\text { samples (tanks) }\end{array}$ \\
\hline Am-241 & 1320 & 317 & $182(15)$ & $135(13)$ \\
Cs-137 & 1571 & 1123 & $825(21)$ & $302(26)$ \\
Pu-238 & 324 & $14+193$ & $81(9)$ & $126(15)$ \\
Pu-239 & 708 & 330 & $222(15)$ & $108(17)$ \\
Sr-90 & 435 & 258 & $123(10)$ & $135(17)$ \\
\hline
\end{tabular}

Initially, all the Pu-238 TCD records flagged with "Data Qualifiers" equal to "C," "R," "UC," "UR," "J," "U," or "UJ" were removed prior to bootstrapping. The majority of these records were assigned below detection " $U$ " codes. Because there were so few records (14) with results greater than the detection limit, $193 \mathrm{Pu}-238$ records with "J," "U," or "UJ" codes were used in the analysis to provide a minimal amount of data for analysis. The other significant quality control (QC) factor was also related to minimum detection.

The key assumptions used in the bootstrap analysis are

1. All CES type "G" samples were assumed to be $125-\mathrm{ml}$ liquid grab samples.

2. All CES samples not labeled as type "G" were assumed to be solid (this is known to be inaccurate because liquid samples from tanks AW-101 and SY-103 were assigned to the solids category; however, this is a conservative assumption since solid concentrations are generally higher than liquid concentrations with the possible exception of Cs-137).

3. Radionuclide concentration is independent of sample mass; in particular, concentration and mass are not directly correlated.

4. The sample distribution of concentrations extracted from the TCD is representative of a random sample from the unknown concentration distribution for the samples stored at the 222-S Laboratory. 


\subsection{Total Curie Estimations Based on Smoothed Bootstrapping}

The total curies associated with each radionuclide retained in the waste samples stored at the 222-S Laboratory can be estimated from the TCD data when combined with the mass for each stored sample. However, as with any estimation technique there exists a certain degree of uncertainty associated with the final result. Therefore, it is important not only to obtain the best "one number" estimate of the total curies, but also to provide an interval estimate reflecting the uncertainty associated with sampling. In this report the uncertainty associated with estimating the total curies for each radionuclide of concern is specified in terms of $95 \%$ and $99 \%$ upper bound estimates. If the bootstrapping sampling distribution accurately reflects the sampling distribution of the estimator of total curies, then one could state with $95 \%$ or $99 \%$ confidence that the actual inventory does not exceed the 95 th or 99 th percentile, respectively, of the bootstrapped sampling distribution.

To understand the bootstrapping technique used to predict the curie inventory consider the following example. Suppose that a complete set of radiochemistry results did exist for each sample currently listed in the 222-S Laboratory's CES database (WHC May 30, 1996) and that, for whatever reason, it was impractical to use all the samples to calculate the total curie content. In this case an estimate of total curies could be made by randomly drawing 100 samples from the CES database and multiplying the curies per gram values by the associated mass values. This 100-sample estimate would not be exact, however, because the entire set of samples had not been included in the calculation. If the 100-sample process was repeated to obtain a second total curies estimate, a comparison of the two estimates would yield a rough idea of the uncertainty associated with the method. If the 100-sample process is carried out 10,000 times using a computer, and the collection of estimates (an estimate of the "total curies sampling distribution") are examined, a best estimate of the true total curies and a conservative estimate can be found. A useful and conservative estimate could be the 99th percentile of the estimated sampling distribution.

The smoothed-bootstrapping technique in this application produces an estimate of a total curies sampling distribution by an "empirical" Monte Carlo simulation approach. The sampling distribution estimate comes from 10,000 estimates of total curies. Each total curies estimation is then calculated, only drawing concentrations from the empirical distribution and matching these randomly to the samples in the CES inventory. An estimation of the total curies is then the sum of the products of these matched pairs.

Relevant curie concentration data for each radionuclide of concern was extracted from TCD. These data were separated into liquid and solid subsets based on the reported units, $\mathrm{uCi} / \mathrm{L}$ and $\mathrm{uCi} / \mathrm{gm}$, respectively. A substantial number of concentrations (possibly, higher than 40\%) labeled "Minimum Detection Limit" were removed from each subset. It is assumed that their removal resulted in a conservative upward bias of the total curies estimated. Concentration results for all aggregation levels were retained in the analysis.

Next, estimates of probability distribution functions (PDFs) and the cumulative distribution functions (CDFs) for each radionuclide in terms of liquid and solid subsets were found (ten in all). These distribution function estimates are referred to in this report as empirical distri- 
bution functions (EDFs). The EDFs are the basis for estimating the liquid, solid, and combined total curies sampling distributions for each radionuclide. These EDFs are presented in Figures 3.1 through 3.10.

In the final step of the bootstrapping method values were randomly drawn from the appropriate solids concentration EDF-one value for each sample on the CES solids list-and then the total curies associated with solids was estimated by summing the products of sample masses and the randomly assigned curie concentration values. An estimate of the liquids total curies was obtained in a similar fashion. The process was repeated 10,000 times to obtain estimates of the solids, liquids, and the combined total curies sampling distributions. The estimate of the combined total curies distribution was obtained by adding an estimate of total curies in solid form to an estimate of total curies in liquid form. The resultant bootstrap estimates of the sampling distributions are presented in Figures 3.11 through 3.15.

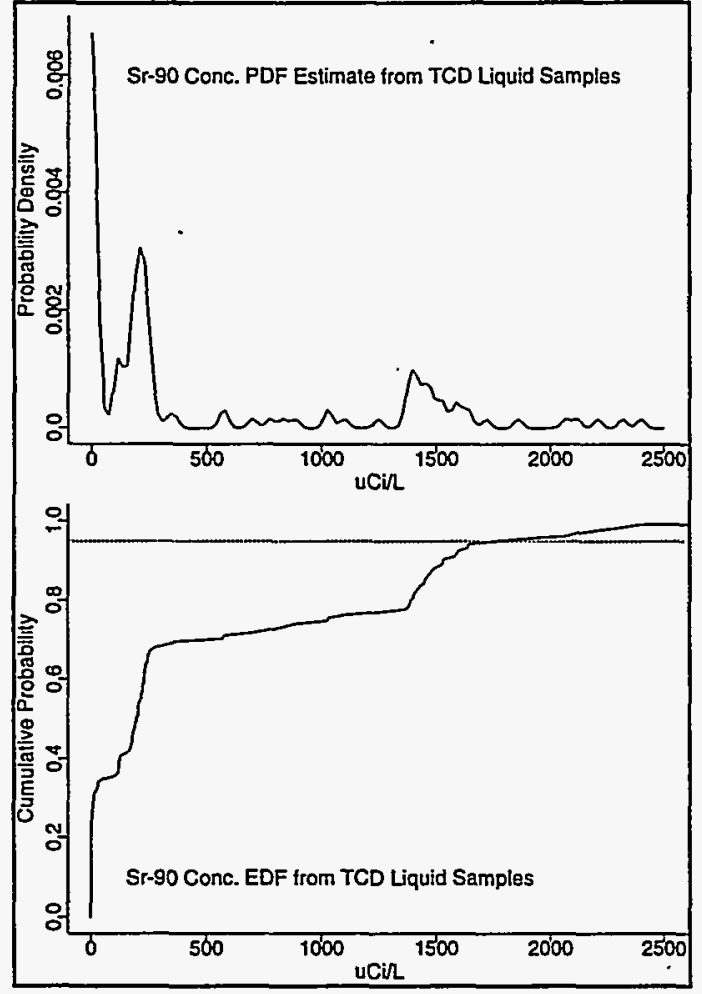

Figure 3.1 Estimates of Sr-90 Probability Density and Distribution Functions for Liquid Samples

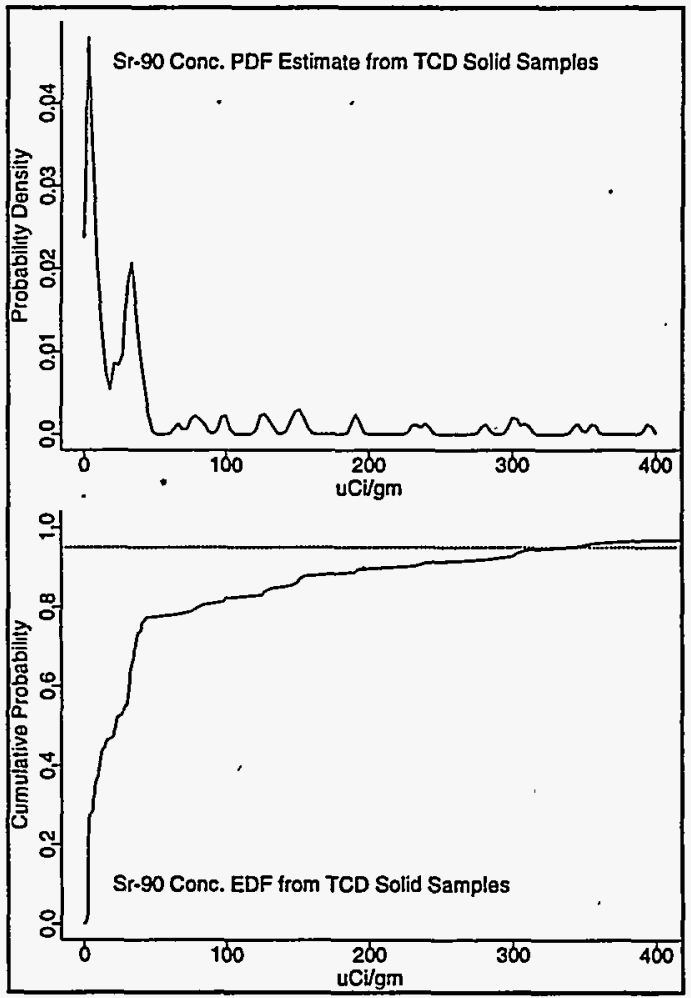

Figure 3.2 Estimates of Sr-90

Probability Density and Distribution Functions for Solid Samples 


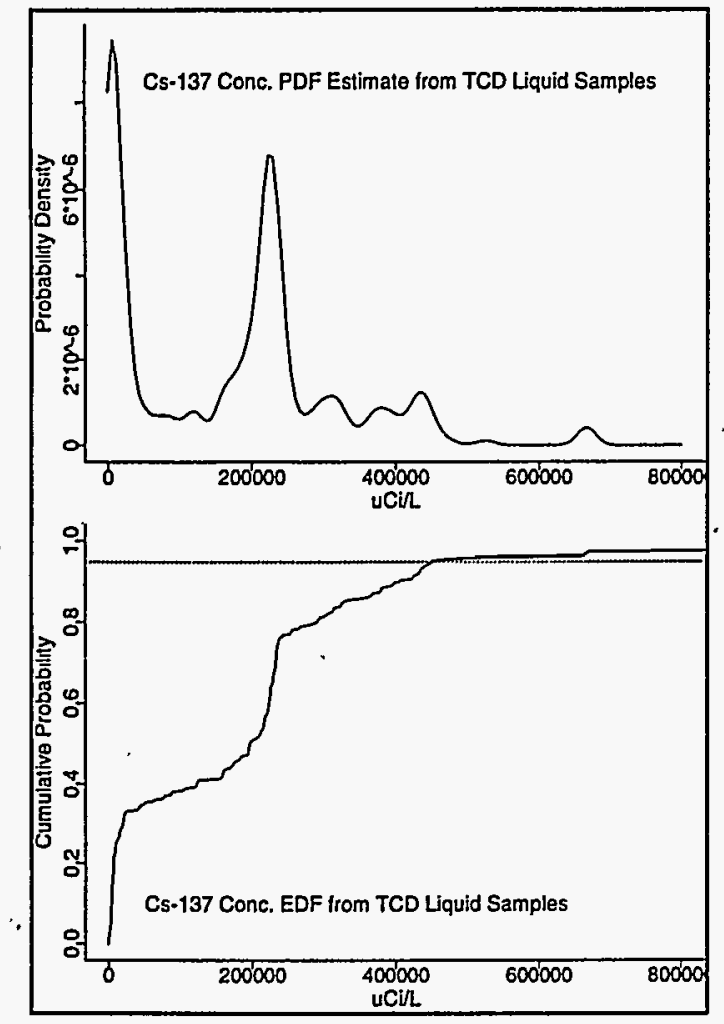

Figure 3.3 Estimates of Cs-137

Probability Density and Distribution

Functions for Liquid Samples

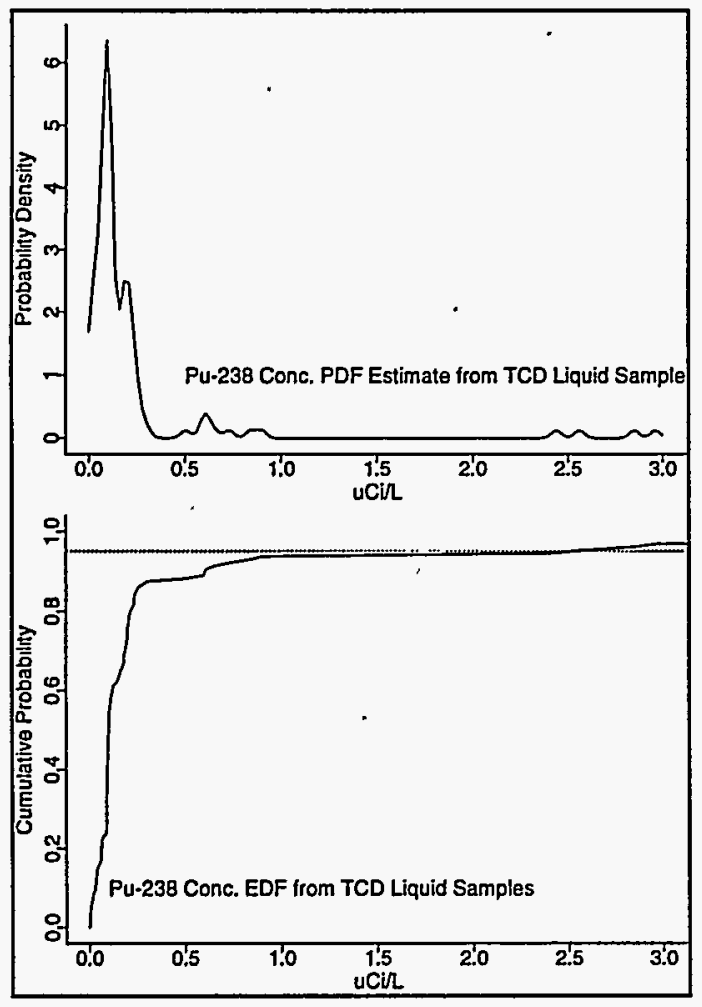

Figure 3.5 Estimates of Pu-238

Probability Density and Distribution

Functions for Liquid Samples

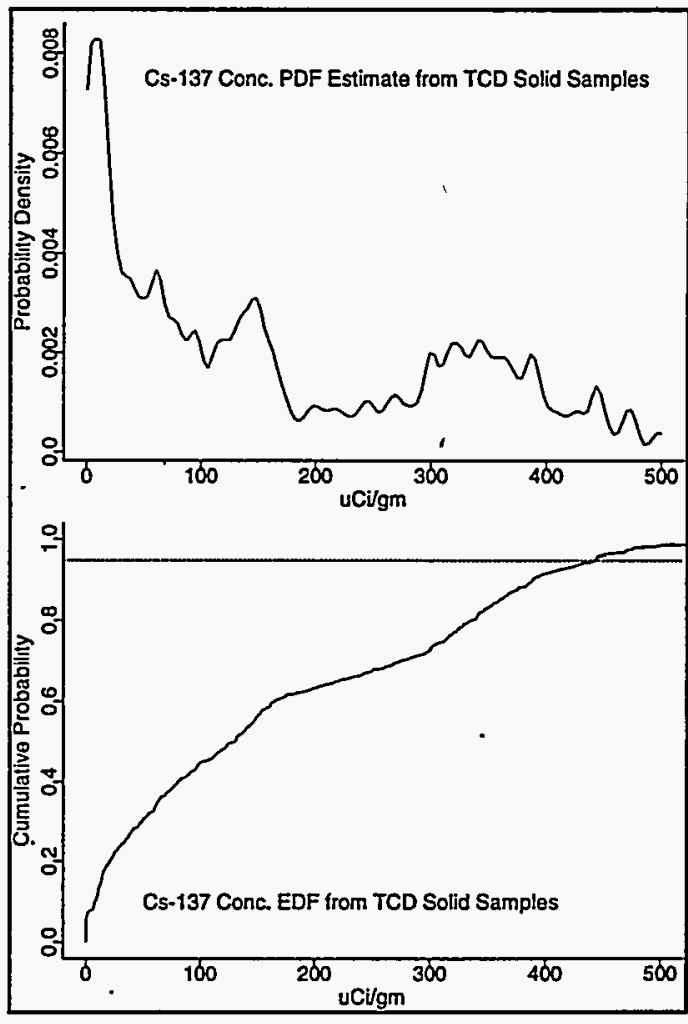

Figure 3.4 Estimates of Cs-137 Probability Density and Distribution Functions for Solid Samples

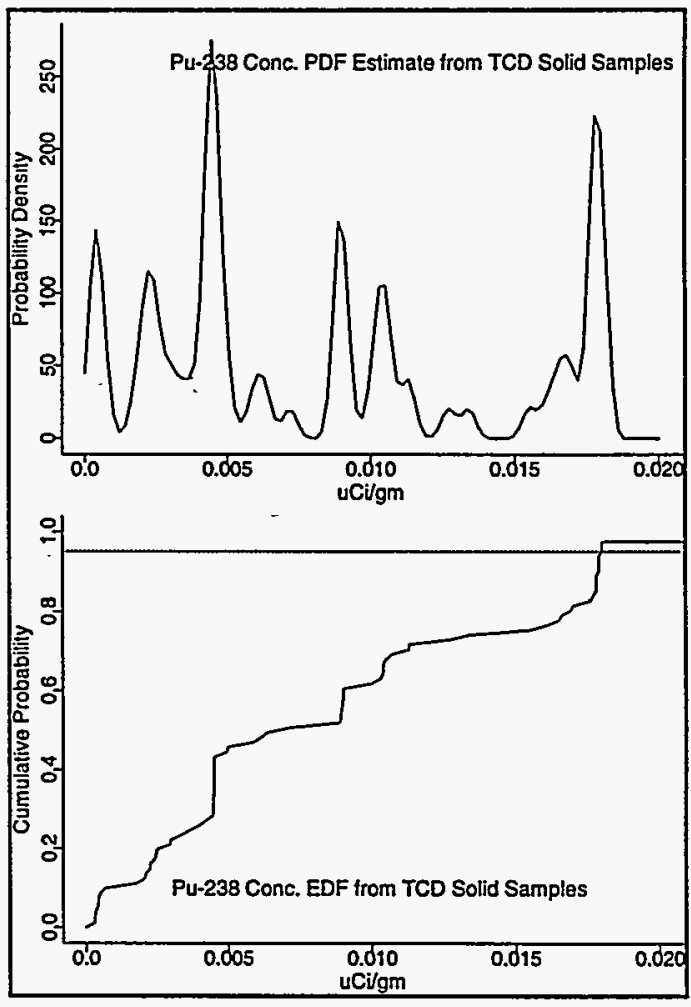

Figure 3.6 Estimates of Pu-238

Probability Density and Distribution Functions for Solid Samples 


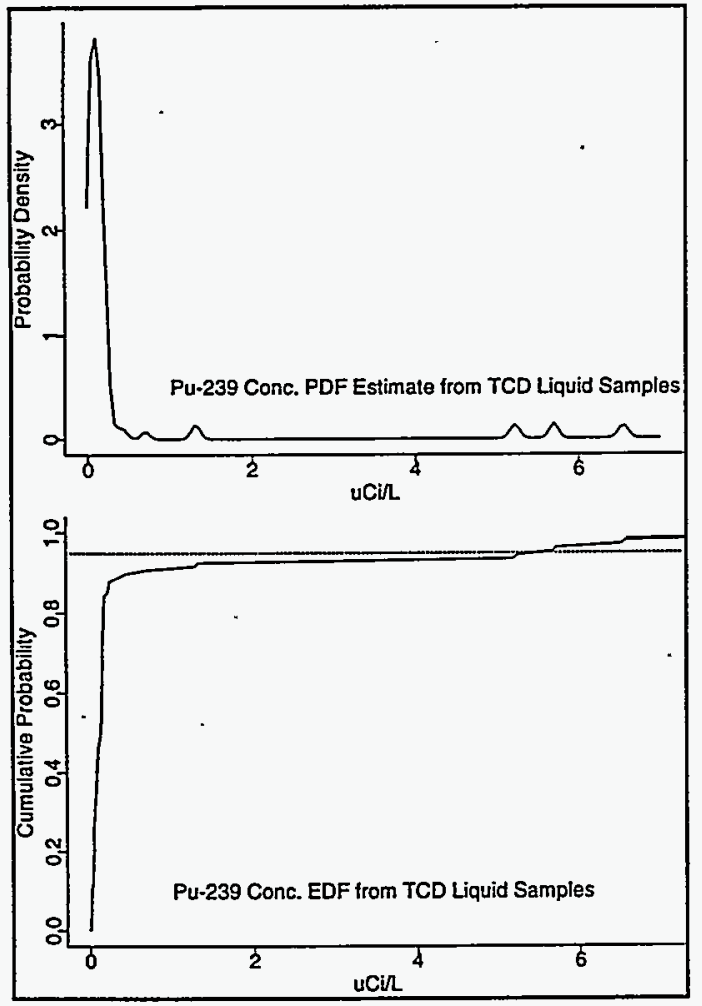

Figure 3.7 Estimates of $\mathrm{Pu}-239$ Probability Density and Distribution Functions for Liquid Samples

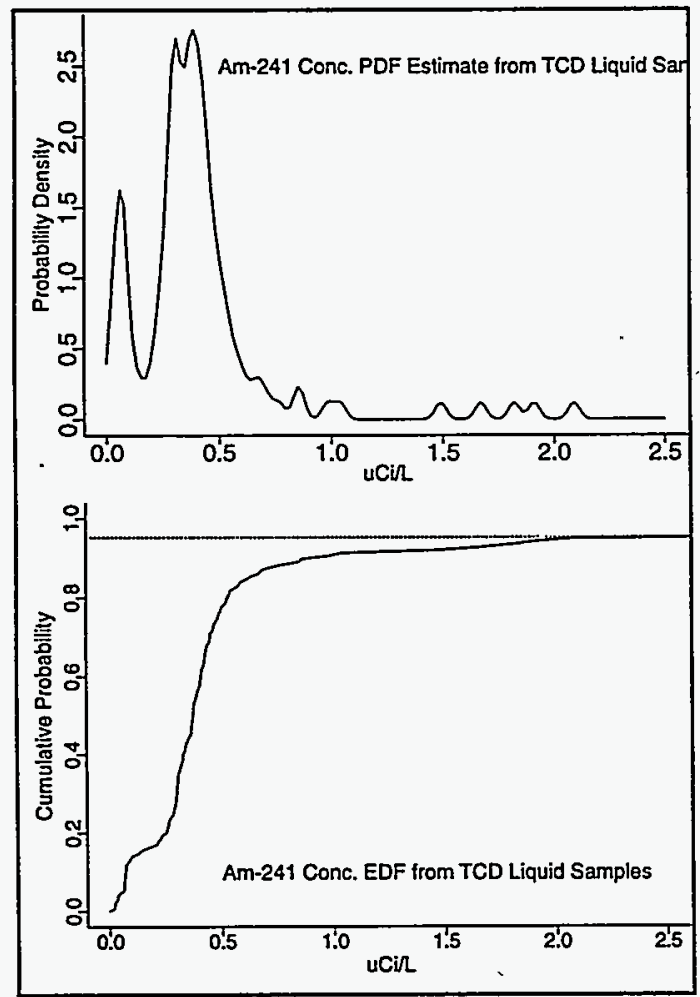

Figure 3.9 Estimates of Am-241 Probability Density and Distribution Functions for Liquid Samples

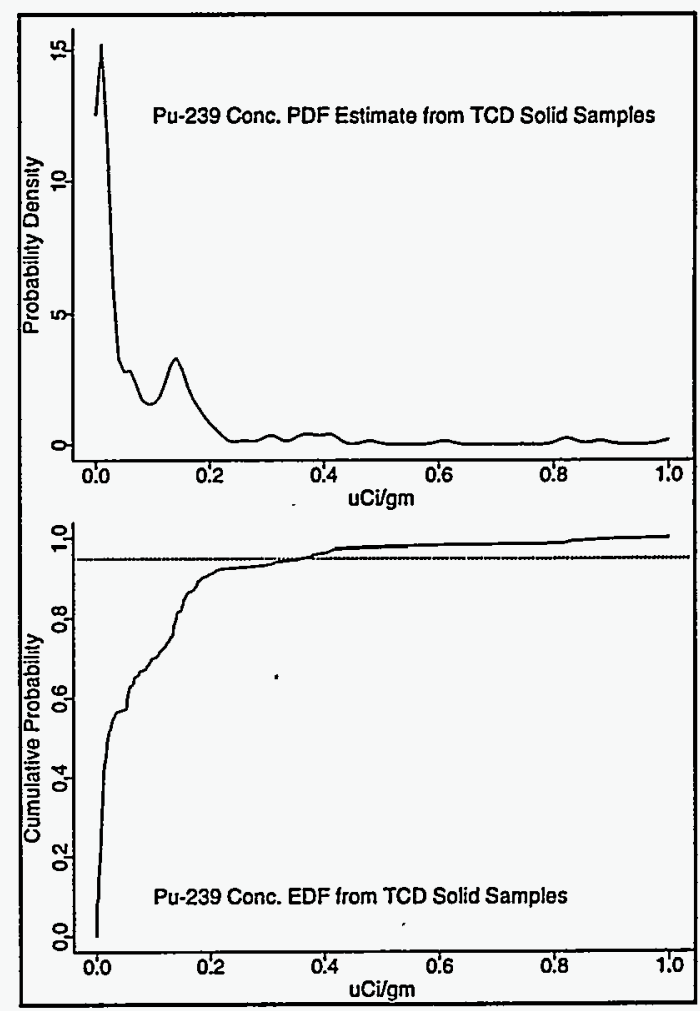

Figure 3.8 Estimates of $\mathbf{P u}-239$ Probability Density and Distribution Functions for Solid Samples

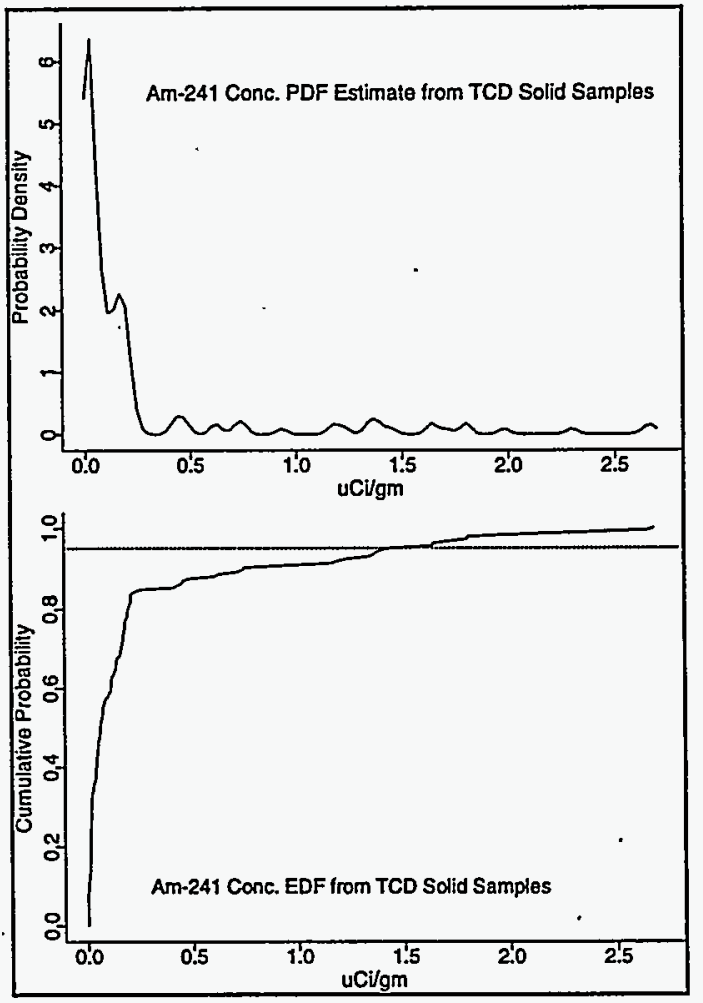

Figure 3.10 Estimates of Am-241 Probability Density and Distribution Functions for Solid Samples 


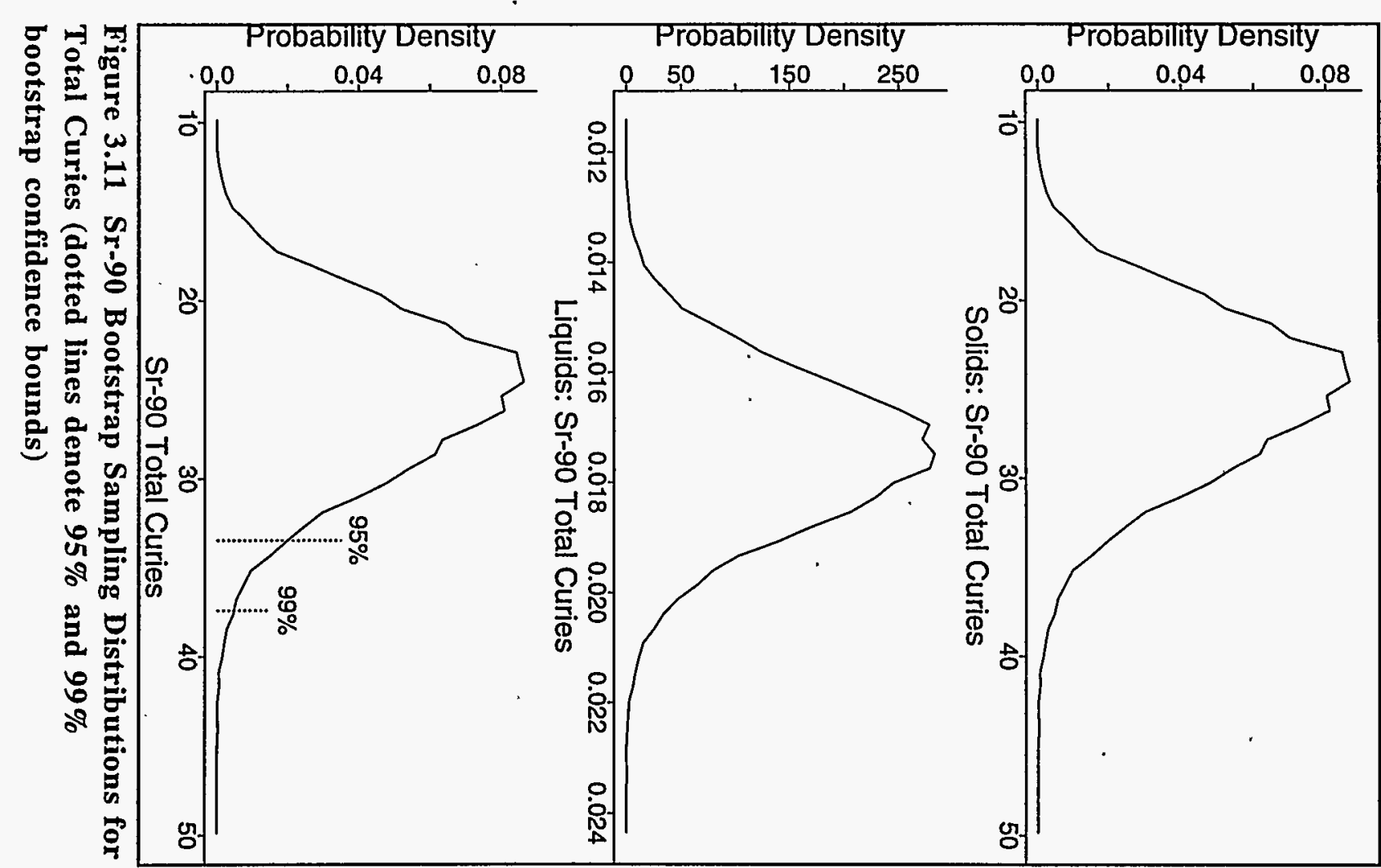




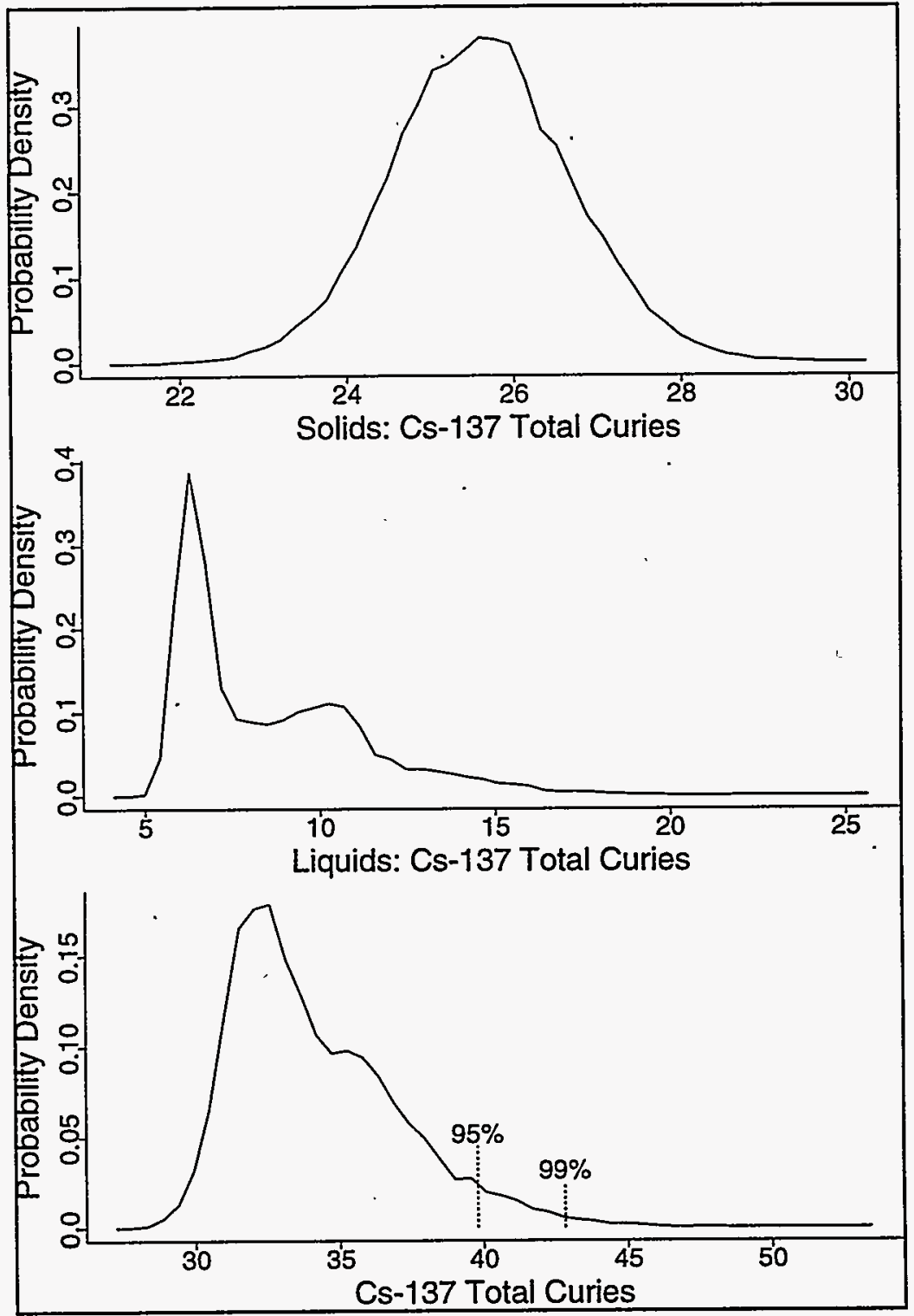

Figure 3.12 Cs-137 Bootstrap Sampling Distributions for Total Curies (dotted lines denote $95 \%$ and $99 \%$ bootstrap confidence bounds) 


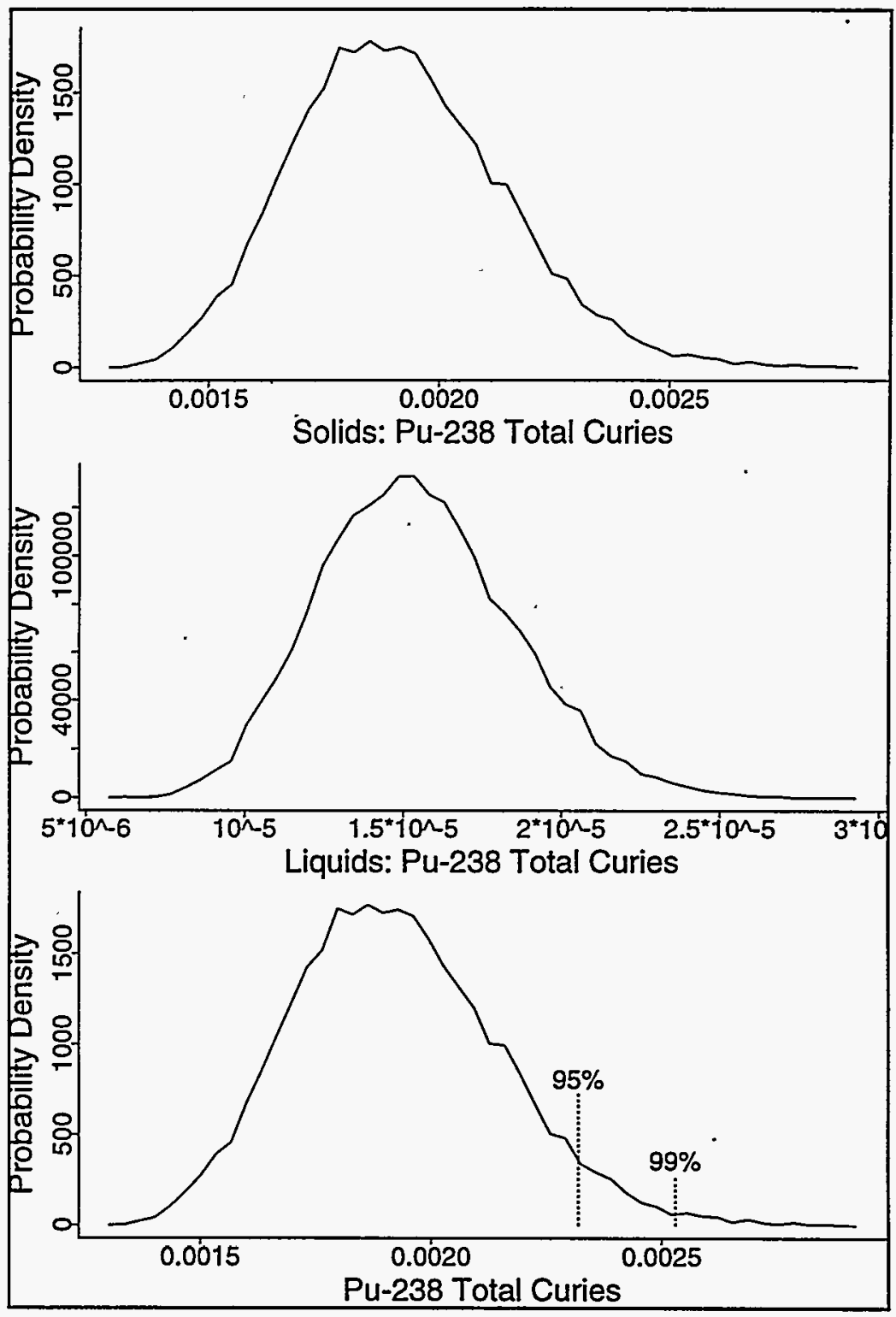

Figure 3.13 Pu-238 Bootstrap Sampling Distributions for Total Curies (dotted lines denote $95 \%$ and $99 \%$ bootstrap confidence bounds) 


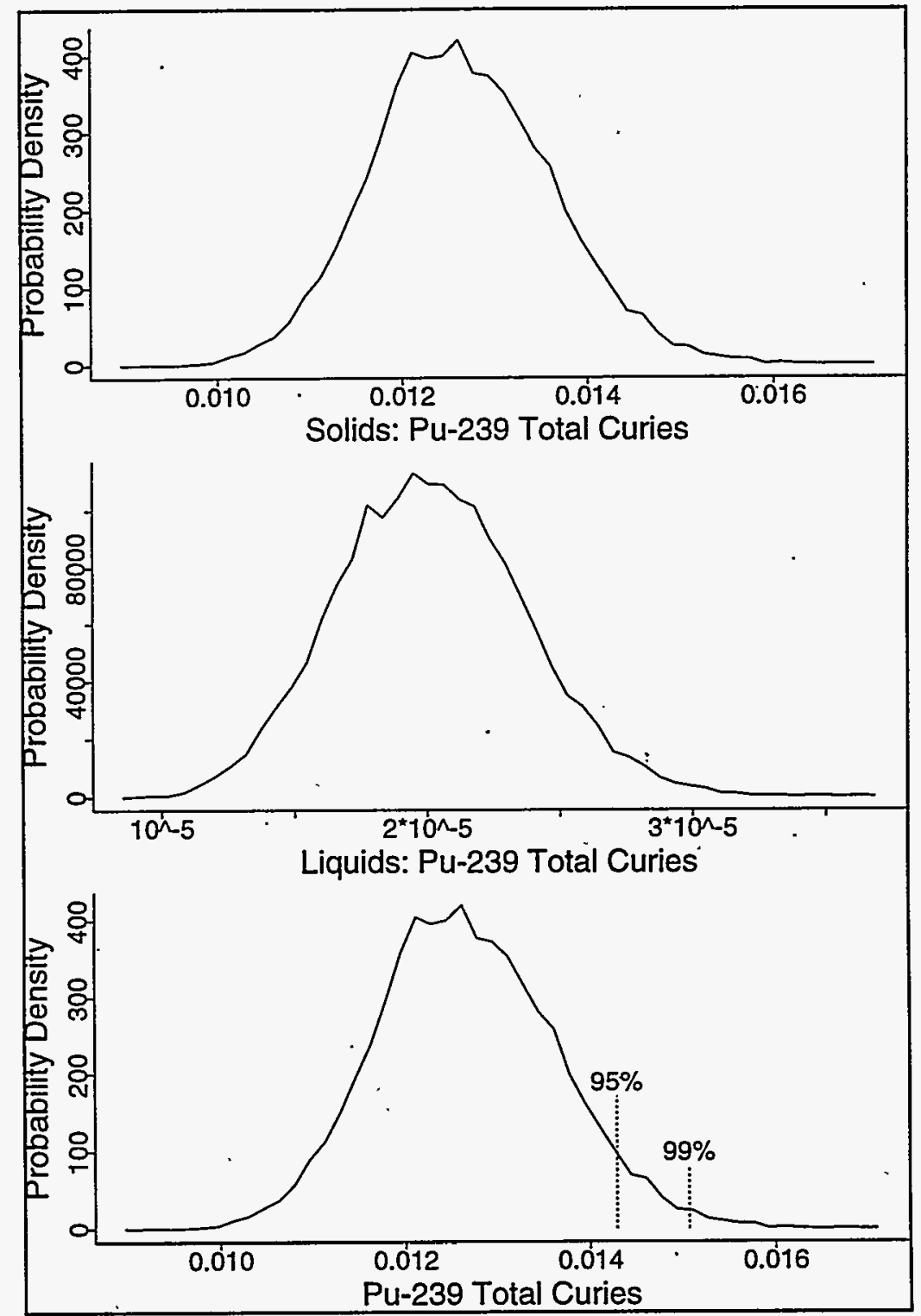

Figure 3.14 Pu-239 Bootstrap Sampling Distributions for Total Curies (dotted lines denote $95 \%$ and $99 \%$ bootstrap confidence bounds) 


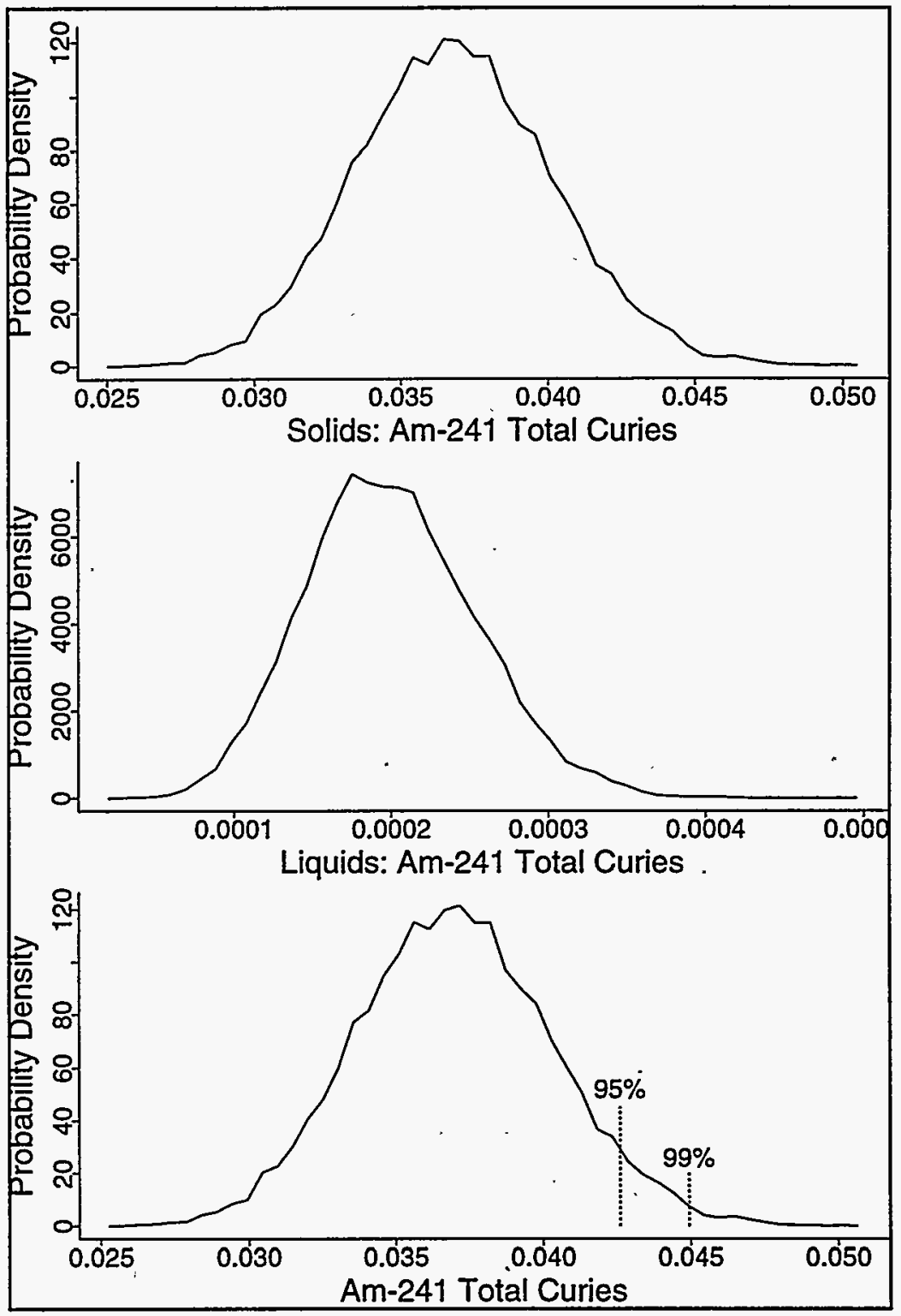

Figure 3.15 Am-241 Bootstrap Sampling Distributions for Total Curies (dotted lines denote $95 \%$ and $99 \%$ bootstrap confidence bounds) 


\subsection{Summary of Waste Tank Data Analysis}

Best estimates, and $95 \%$ and $99 \%$ upper confidence values, on the curie content of the radionuclides retained in the samples stored at the 222-S Laboratory were taken from results shown in Figures 3.11 through 3.15 and are summarized in Table 3.2. Best estimate values are the median of the bootstrapped sampling distributions. These medians are very close to the total curie estimates obtained by multiplying the simple average concentrations times the total masses. A reasonable non-bootstrap estimate of the upper bound is not as easily obtained and, hence, the need for bootstrapping. A comparison of the best estimate and $99 \%$ upper confidence bound values provides a sense of variation in the "sum-of-the-products" total curies estimation method.

Table 3.2 Summary of Best Estimate and 99\% Curie Inventory Values for Tank Samples

\begin{tabular}{lccc}
\hline Isotope & $\begin{array}{c}\text { Best Estimate } \\
\text { (curies) }\end{array}$ & $\begin{array}{c}\text { 95\% Upper } \\
\text { Confidence. Bound } \\
\text { (curies) }\end{array}$ & $\begin{array}{c}\text { 99\% Upper } \\
\text { Confidence Bound } \\
\text { (curies) }\end{array}$ \\
\hline Sr-90 & 25.1 & 33.5 & 37.4 \\
Cs-137 & 33.5 & 39.8 & .42 .8 \\
Pu-238 & 0.00191 & 0.00232 & 0.00253 \\
Pu-239 & 0.0126 & 0.0143 & 0.0151 \\
Am-241 & 0.037 & 0.0426 & 0.045 \\
\hline
\end{tabular}




\subsection{Comparison of ISB Methodology Estimates and Bootstrapped Estimates}

The prediction of total curie inventory for each radionuclide of concern, based on the methodology presented in Weaver (1996), is simply equal to total CESs multiplied by curies per CES for each radionuclide. Based on this calculation, using 319.7 CESs (WHC May 30, 1996) and assuming a maximum inventory limit of 720 CESs, the Laboratory's current inventory is approximately $44 \%$ of its allowed inventory. The details of these calculations are provided in Table 4.1.

Table 4.1 Current 222-S Laboratory Based on ISB Methodology

\begin{tabular}{lccccc}
\hline Isotope & $\begin{array}{c}\text { Curies/CES } \\
\text { per 222-S } \\
\text { ISB }\end{array}$ & $\begin{array}{c}\text { Reported } \\
\text { Inventory } \\
\text { (CES) }\end{array}$ & $\begin{array}{c}\text { Inventory } \\
\text { based on ISB } \\
\text { methods } \\
\text { (curies) }\end{array}$ & $\begin{array}{c}\text { Inventory } \\
\text { Limit } \\
\text { (curies) } \\
\mathbf{7 2 0 ~ C E S s ~}\end{array}$ & $\begin{array}{c}\text { \% of Max } \\
\text { Inventory } \\
\text { Limit }\end{array}$ \\
\hline Sr-90 & 0.6131 & 319.7 & 196.0 & 441.4 & $44 \%$ \\
Cs-137 & 1.581 & 319.7 & 505.4 & 1138.3 & $44 \%$ \\
Pu-238 & $5.43 \mathrm{E}-04$ & 319.7 & 0.2 & 0.4 & $44 \%$ \\
Pu-239 & 0.01375 & 319.7 & 4.4 & 9.9 & $44 \%$ \\
Am-241 & $3.69 \mathrm{E}-03$ & 319.7 & 1.2 & 2.7 & $44 \%$ \\
\hline
\end{tabular}

Best estimate values of total curie inventory for each radionuclide of concern in the 222-S Laboratory' inventory and 99\% upper bound values are repeated in Table 4.2 along with their corresponding percentages in terms of maximum allowed inventory.

Table 4.2 Estimate of Total Curies Associated with Waste Tank Samples Stored at the 222-S Laboratory as of May 30, 1996

\begin{tabular}{|c|c|c|c|c|}
\hline Isotope & $\begin{array}{c}\text { Best Estimate of } \\
\text { Inventory } \\
\text { (curies) }\end{array}$ & $\begin{array}{c}\% \text { of Max. limit } \\
\text { based on } 720 \\
\text { CESs }\end{array}$ & $\begin{array}{l}99 \% \text { upper bound } \\
\text { on Inventory } \\
\text { (curies) }\end{array}$ & $\begin{array}{c}\% \text { of Max. limit } \\
\text { based on } 720 \\
\text { CESs }\end{array}$ \\
\hline $\operatorname{Sr}-90$ & 25.1 & $5.69 \%$ & 37.4 & $8.47 \%$ \\
\hline Cs-137 & 33.5 & $2.94 \%$ & 42.8 & $3.76 \%$ \\
\hline $\mathrm{Pu}-238$ & 0.00191 & $0.48 \%$ & 0.00253 & $0.63 \%$ \\
\hline Pu-239 & 0.0126 & $0.13 \%$ & 0.0151 & $0.15 \%$ \\
\hline $\mathrm{Am}-241$ & 0.037 & $1.37 \%$ & 0.045 & $1.67 \%$ \\
\hline
\end{tabular}





\subsection{Conclusions and Recommendations}

In conclusion, we have developed a methodology based on a statistical technique referred to as "smoothed bootstrapping" and applied it to the large number of radiochemistry results data recorded in the TCD to predict the 222-S Laboratory's inventory of radionuclides currently retained in the stored waste tank samples. Additionally, a comparison of the predicted inventory as determined by this method to the inventory predicted based on the method described in Weaver (1996) demonstrates the following two conclusions: 1) that the method described by Weaver is very conservative and is an acceptable method for controlling inventory (providing it does not restrict future facility operations); and 2) that the Laboratory's actual inventory may be, at least, one order of magnitude less than what is currently predicted.

The 222-S Laboratory should re-baseline its radionuclide inventory using one of the following options:

Option 1 - Re-baseline the current inventory (319.7 CESs) to be equal to the $99 \%$ upper bound estimate determined in this report and continue using the existing methods to assign CES values for new samples being logged into the Laboratory. Periodically re-perform (e.g,, once the inventory approaches $600 \mathrm{CES}$ ) the same statistical evaluation using the most up-to-date data to predict the actual inventory and assign and effective total CES based on the most recent analysis. This option is the least difficult and least costly to implement at the Laboratory.

Option 2 - Re-baseline the current inventory (319.7 CESs) to be equal to the $99 \%$ upper bounds determined in this report and re-define the CES values applied to incoming samples based on further analyses of data obtained from TWINS. Develop a system to periodically verify and validate the newly created CES values. It is conceivable that as the characterization of various tanks at the Hanford Site continues the distribution of sample results will change and therefore need to be periodically corrected. This option would be more difficult to implement but would provide a more accurate method of predicting the daily inventory.

Option 3 - Re-baseline the current inventory (319.7 CESs) to be equal to the $99 \%$ upper bound estimate determined in this report. Institute procedures to track all new samples by weight and radionuclide concentration. Calculate future inventories based on a complete census of all samples in the inventory on a regular basis. This option would provide the most accurate method of predicting Laboratory inventory, but would be the most difficult and costly to implement. 


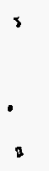




\subsection{References}

Eckerman, K.F., A.B. Wolbarst, and A.C. Richardson. 1988. Limiting Values of Radionuclide Intake and Air Concentration and Dose Conversion Factors for Inhalation, Submersion, and Ingestion. Federal Guidance Report No. 11, Oak Ridge National Laboratory, Oak Ridge, Tennessee.

Pacific Northwest National Laboratory (PNNL). June 17, 1996. Tank Waste Information Network System (TWINS) Reference, [Online report]. Available URL:

http://twins.pnl.gov:8001/TCD/main.html

Weaver LL. 1996. 222-S Laboratory Interim Safety Basis. WHC-SD-CP-ISB-002 Rev. 1, Westinghouse Hanford Company, Richland, Washington.

Westinghouse Hanford Company (WHC). May 30, 1996. 222-S CES Database, [QuatroPro]. Available: Westinghouse Hanford Company, Richland, Washington.

U.S. Department of Energy (DOE). 1992. Nuclear Safety Analysis Reports. DOE Order 5480.23 . 


\section{Distribution}

No. of

Copies

OFFSITE

12 DOE/Office of Scientific and Technical Information

\section{ONSITE}

10 Westinghouse Hanford Company

S. L. Brey (4)

C. T. Narquis (2)

L. L. Weaver (2)

T. L. Welsh (2)
No. of

Copies

11 Pacific Northwest National Laboratory

D. S. Daly (2)

C. L. Painter (2)

D. S. Walters

Publishing Coordination

Technical Reports Files (5) 